\title{
Reciprocal personal/public protection for Covid-19 with mask discriminating mouth and nose
}

\author{
Yijun Yuan \\ University of Nottingham, NG7 2RD, UK, \\ University of South China, 28, West Changsheng Road Hengyang, Hunan, 421001, China \\ yuanyijunc@msn.com
}

\begin{abstract}
Reciprocal Personal/Public Protection (RPPP) featured with source control is introduced, Mask Discriminating Mouth and Nose (MDMN) is employed to serve the purpose, which includes polymer based mouth cover with optional nose cover. The new knowledge that mouth is a primary, active and dominant source of the virus has been well established, which is the base of MDMN. Source classification and related source control tools are discussed, mouth cover is recommended as the tool prioritized to use. Liquid droplets is identified as a hard issue related to mask, liquid droplets, mask fitting, comfort and facial recognition constitute real challenges of mask in addition to efficiency, All of these have been addressed with MDMN. Comparisons between MDMN and masks/face covering are taken on four aspects: efficiency and efficacy, tolerance and comfort, cost and waste, and civil rights and public interest. Mouth cover is recommended to replace the face covering and act as both a personal tool and a public utensil, mouth cover with nose cover can provide better protection than N95 etc. RPPP with MDMN, could be an alternative for lockdown, a parallel strategy to vaccine, and a collectively living way during the pandemic era. MDMN, featured with high efficiency protection, high degree comfort, easy wearing, tight-fitting, easy facial recognition \& communication, reusability, cost-effective, environment friendly and scale manufacturing more readily and widely etc., is a simple and sustainable solution, which is essential for ordinary people to keep wearing it properly for protection.
\end{abstract}

Keywords: reciprocal personal/public protection, mask discriminating mouth and nose, mouth cover, mask, face covering, source control, source classification, Covid-19, active source, , liquid droplets 


\section{Introduction}

The ongoing COVID-19 pandemic tests us in almost every aspect, particularly the relationship between people. According to CDC [1], the coronavirus primarily spreads from person to person and not easily from a contaminated surface, the virus spreads easily and sustainably between people, the virus travels through the droplets a person produces when talking, coughing, etc., an individual does not need to feel sick or show symptoms to spread it.

The dominant route for the spread of COVID-19 between people is from person to person via air, namely "person - air - person", called airborne transmission $[2,3]$.

As early as 1987, As a result of the investigations conducted during the past five decades, in the review on spread of viral infections by aerosols, air was recognized as an important means for virus's transmission. Depending on environmental conditions, many of these viruses can survive in an airborne state anywhere from several hours to several days. This can result in the aerial dissemination of such infectious agents over distances of several kilometres [4].

Airborne transmission through droplets and aerosols enables virus to spread efficiently among humans, causing outbreaks that are difficult to control.

The virus such as influenza was found to have greater infectivity when introduced by the airborne route rather than by instillation in the nose [5].

Compared to other means of virus inoculation, aerosol challenge may require smaller numbers of virus infective units to infect a susceptible host [4].

As a low tech intervention of the transmission, Masks or face coverings have become a ubiquitous symbol of the coronavirus pandemic. But as symbolism and controversy were sewn into masks, scientists are trying to provide answers about how effectively those masks prevent transmission of the coronavirus, and what role they should play in efforts to limit the pathogen's spread. Objectively, no matter how divided we are on wearing mask, we can find some common ground: nobody likes wearing a mask as it is alien to people. It becomes clear that scientists need to develop masks that are not only effective, but also fit well and feel good. Scientists with Empathy should have kind of power to enable a connection between people rather than alienating them further. 
There may be a variety of downsides arising from mask production, mask use and aftermath, including: discomfort, sense of difficulty breathing, communication problems, economic cost and PPE waste etc.

When the barriers are understood, they become addressable with new approaches instead of using the current masks with their intrinsic issues.

\section{New Approach}

The new approach called reciprocity personal/public protection (RPPP) with mask discriminating mouth and nose (MDMN).

\subsection{Reciprocity personal/public protection (RPPP)}

Reciprocity personal/public protection (RPPP) concept is illustrated as following:

Given a group of people, assumed three scenarios:

A: all without mask except one

B: all with a mask

C: all with mask except one

The situation A is typical personal protection (PP); the situation $\mathrm{B}$ is the so called Reciprocity personal/public protection(RPPP), it means every wearer emit less pathogens to protect others and benefit each other; for situation $\mathrm{C}$, the wearer protect each other and also protect the one without mask, but the Reciprocity personal/public protection get a hole as the one person without mask does protect others, more person in a group without mask, more holes for the Reciprocity personal/public protection(RPPP), and more like personal protection $(\mathrm{PP})$.

\subsection{Evidence for Source}

It takes granted that mouth and nose together are recognized as the source of virus-laden droplets, even few literatures mention mouth and nose as sources, let alone discern them as the different sources, it seemed that it is not necessarily to take the effort to identify them when mask, face covering and respirator etc. all treat them as a whole.

The only literature[6] with this identification dated back to 1945, the author revealed the numbers and the sites of origin, of the droplets expelled during expiratory, and find that nearly all of these small droplets originated from the front of mouth, only relatively few, if any, originated from the nose, or from the throat. 
There are still many other literatures with data and information which could be acquired for this identification purpose.

From the published data of the most recent study by S. Asadi et al. [7] and much previous research by L. Morawska et al. [8], it is easily to draw a conclusion that the mouth contribute almost all pathogens expelled from the human respiratory tract during expiratory activities, while nose contribution is trivial. Moreover, the mouth is a much more active source than nose as mouth ejects the pathogen-laden particles into the air at much higher rate.

Many other research findings [9-13], also support the above conclusion.

Asadi et al. [7], focus on speech and breathing as showing in Fig 1, the direct comparison of particles emitted during various types of breathing versus speech demonstrates that even quiet speech yields significantly more particles than normal breathing, more particles escape the respiratory tract if the vocalization is louder.

A

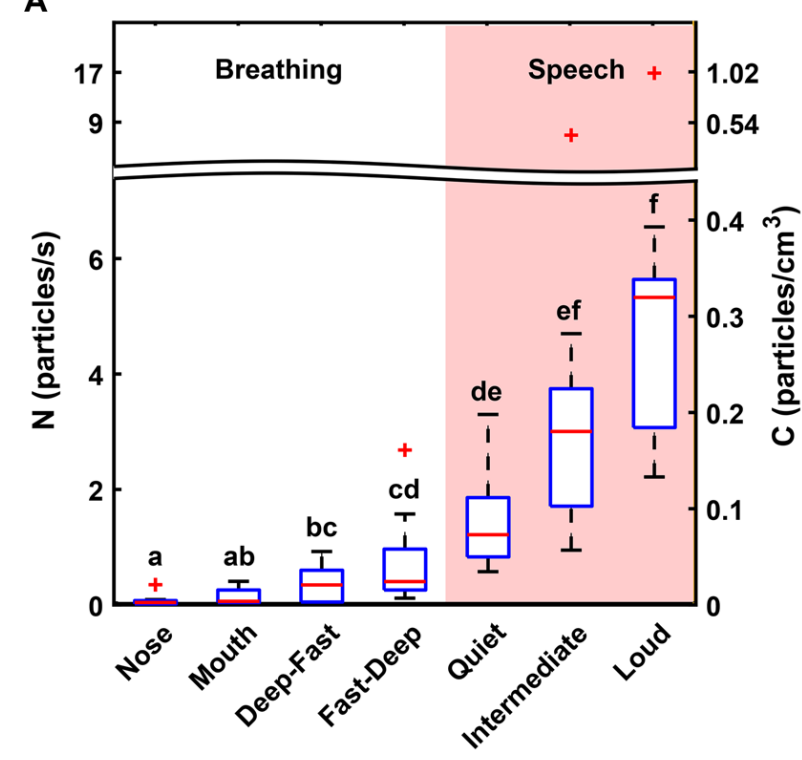

B

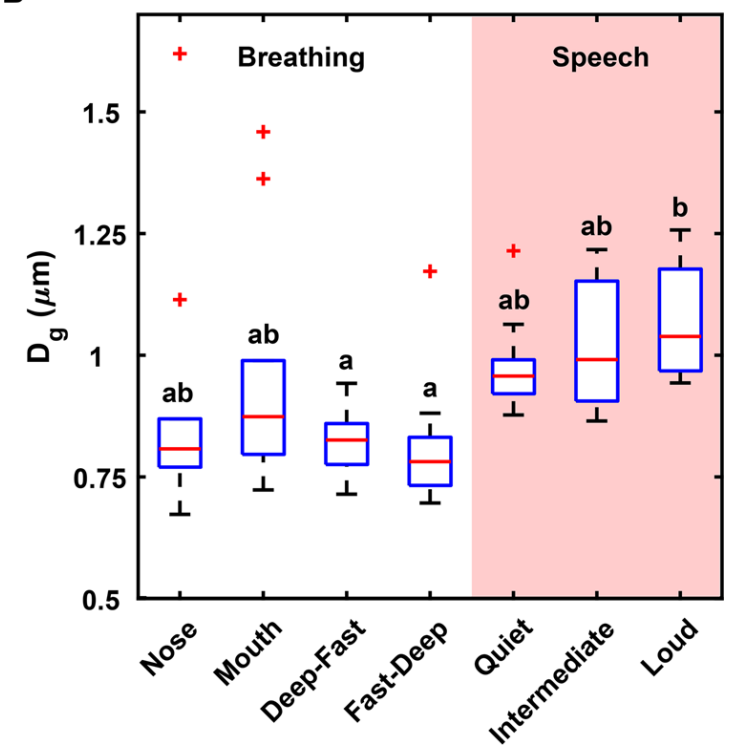

Figure 1. Comparison of (A) emission rate/concentration and (B) corresponding geometric mean diameters of particles emitted during various modes of breathing versus speech at different loudness levels. "Nose" denotes normal nasal breathing; "Mouth" denotes normal mouth breathing;

Further, Normal mouth breathing produce much more airborne droplets than nose breathing, this phenomenon was also observed repeatedly in earlier researches $[9,10]$. 
Asadi et al. (7) established that certain individuals are "speech superemitters" who emit an order of magnitude more aerosol particles than average.

Asadi et al. (7) further established that simply talking in a loud voice would increase the rate at which an infected individual releases pathogen-laden particles into the air, which in turn would increase the probability of transmission to susceptible individuals nearby.

A group of researchers from Heriot-Watt University and the University of Edinburgh in the U.K. [11] develop a mathematical model of someone breathing that provides a general framework to understand the droplet dispersion. The simulations relevant to human respiration show even quiet breathing and heavy breathing make difference, the maximum distance and time travelled by droplets for quiet breathing is much shorter and longer than those for heavy breathing and the as shown in Figure 2, the difference between talking and breathing, or nose breathing should be more striking.

(a)
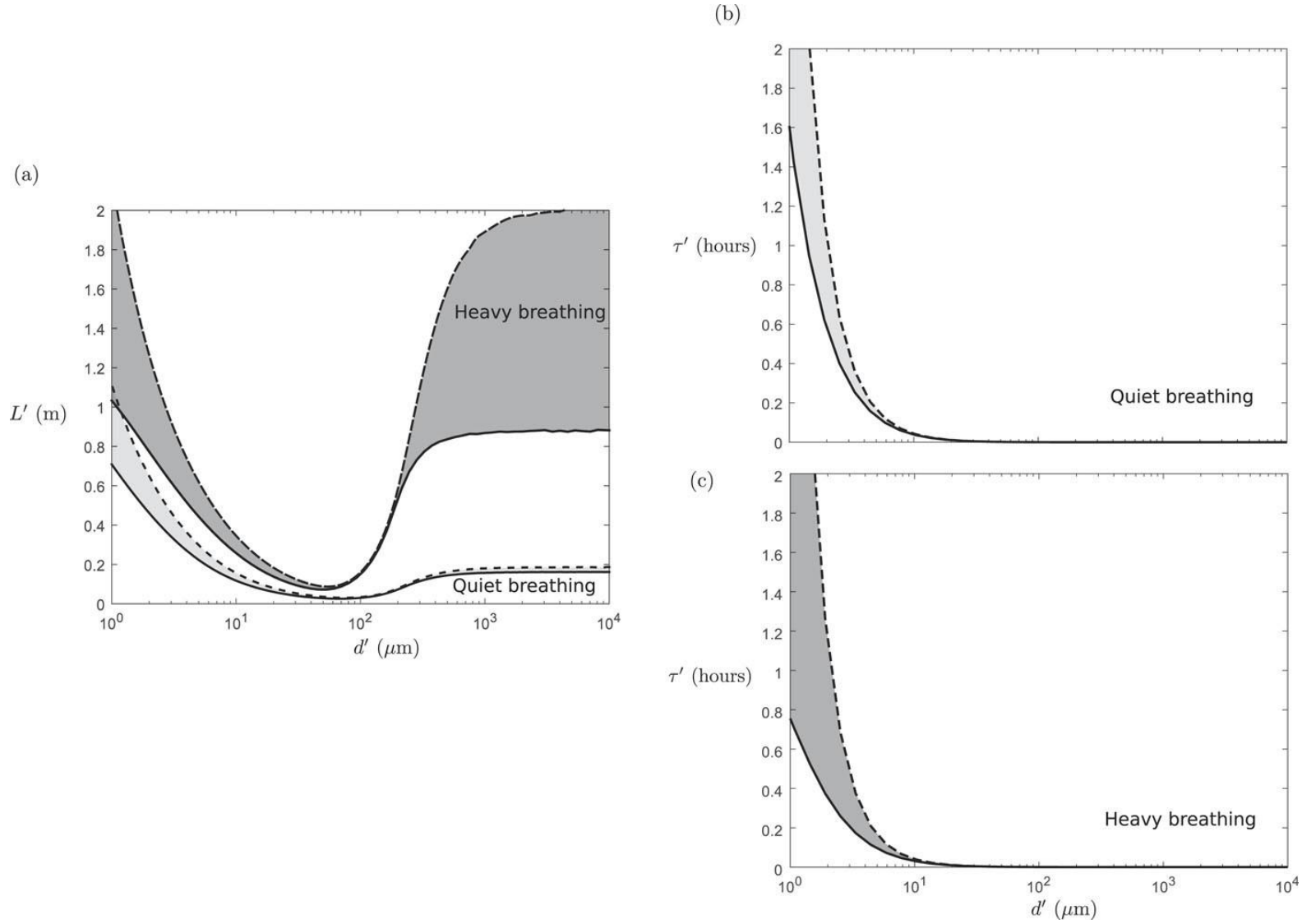

Figure 2. (a) The maximum distance ( $\mathrm{L}^{\prime}$ ) traveled for droplets of various diameters $\left(d^{\prime}\right)$ with quiet and heavy breathing. [(b) and (c)] The total duration of travel $\tau^{\prime}$ corresponding to the value of $L^{\prime}$ for quiet breathing (b) and heavy breathing (c). 
It means that mouth is an active source, while surface is a passive source not easily for pathogen spread [12], and the nose is less active or between active and passive.

L. Morawska [8] conducted the most comprehensive investigation on the droplets produced during different respiratory activities including breathing, vocalization and coughing etc. the nose breathing produced the least droplets, the nose(in)/mouth(out) breathing next to the least, and vocalization the most.

Yan, J. et al. [13] \& Fabian P. et al. [14] test the virus in nose in the air samples and provide direct evidence about nose contribution to the virus.

Yan, J. et al. claimed that nasal shedding was not a significant predictor of aerosol shedding [13].

No human rhinovirus (found in the nose) was detected in exhaled breath samples by Fabian P. et al. [14]

The work of Yan, J. et al. [13].\& Fabian P. et al. [14] implied that the aerosol from nose may contain less or no virus as the quiet nose breathing may have less force to cause the virus shedding.

In summary, literature [7-10] offer evidence of mouth as majority contributor of particles numbers, literature [7] with [11] shows that mouth not only has particles quantity dominance, also the particles itself with high momentum travelled long distance, which means favourable quality for transmission. Literatures $[13,14]$ hint an important implication that the nose may generate aerosol with less virus, which also means mouth particles has favourable quality for transmission.

\subsection{Mask discriminating mouth and nose (MDMN)}

Mouth is the dominant source for pathogens and it is also not necessarily required for normal breathing, it means that the mouth can be "sealed" to control almost all the particles generated but with little breathing block effect. On the other hand, the nose could be with normal filter or even no covering to meet the breathing requirement.

The mouth cover could be a solid cover with a small open equipped with polymer membrane [15] which collect over $99.9 \%$ of the particles, and could be reusable, the cover is preferably made by flexible polymer materials such as silicone [16], which could be tightly fitting to prevent face-seal leakage.

The liquid droplets is another factor to justify the mask with separate mouth cover and nose cover, intuitively, there is a concern that the hot moisture 
expelled from mouth and absorbed by mask, get the mask saturated and clogged which provide a favourable condition [17] for proliferation of pathogen and yielding of bad odour etc., and the masks may act as fomites. The likelihood of the survival of the virus increases roughly by five times under a humid condition as compared to a dry condition [18].

The most recent test work [19] by Emma P. Fischer etc. provide new findings related to liquid droplets, as shown in Figure 3, the droplets counts increase lead to the droplet transmission fraction of fleece mask over 100\%, namely $110 \%$, relative to none. It was also noticed that speaking through some other masks seemed show similar trend with of fleece mask: the apparent increase in droplet count against no mask in that case. This abnormal result was attributed to the breakup of large droplets into several smaller ones when passing through the material [19]. The more plausible explaining is that the liquid droplets emitted from mouth captured by the mask's hydrophilic material, the mask get wetted and clogged gradually, the joint effect of liquid evaporation $[10,20]$ and air force leads to the release of the small particles from the mask.

The research on surface wettability [20] shows that the surface wetting properties can reduce the drying time of droplets, which provides a better understanding of the trend of droplets increase: the more hydrophilic surface, the shorter drying time, the more small particles released from mask and the more droplet counts. The fleece mask with the most hydrophilic surface shows the largest droplet increase, bandana and knitted also show obvious increase for their wettability.

In fact, all filters including the HEPA filter with much higher efficiency than N95, share the same effect of droplets increase due to the liquid droplet, although for high efficiency filter, there is less increase due to the better interception of the droplets emitted from the mask surface. Wilkes etc. [22] observed the same effect in the breathing system's HEPA filters used during anaesthesia, They hypothesise that the viruses, released from the droplet after contact with moisture accumulated on the filter, can be driven onwards by the flow of gas.

Interestingly, the two publications $[19,20]$ simultaneously published, both want to offer recommendation for better masks design, unfortunately, they are contradicting each other. One [19] suggested that materials should be hydrophilic to reduces the drying time and the chances of the infection of virus as likelihood of the survival of the virus decreases greatly under a dry condition compared to a humid condition; while another [20] would suggest that materials 
should be less hydrophilic to avoid released particles from mask due to the evaporation drying process.

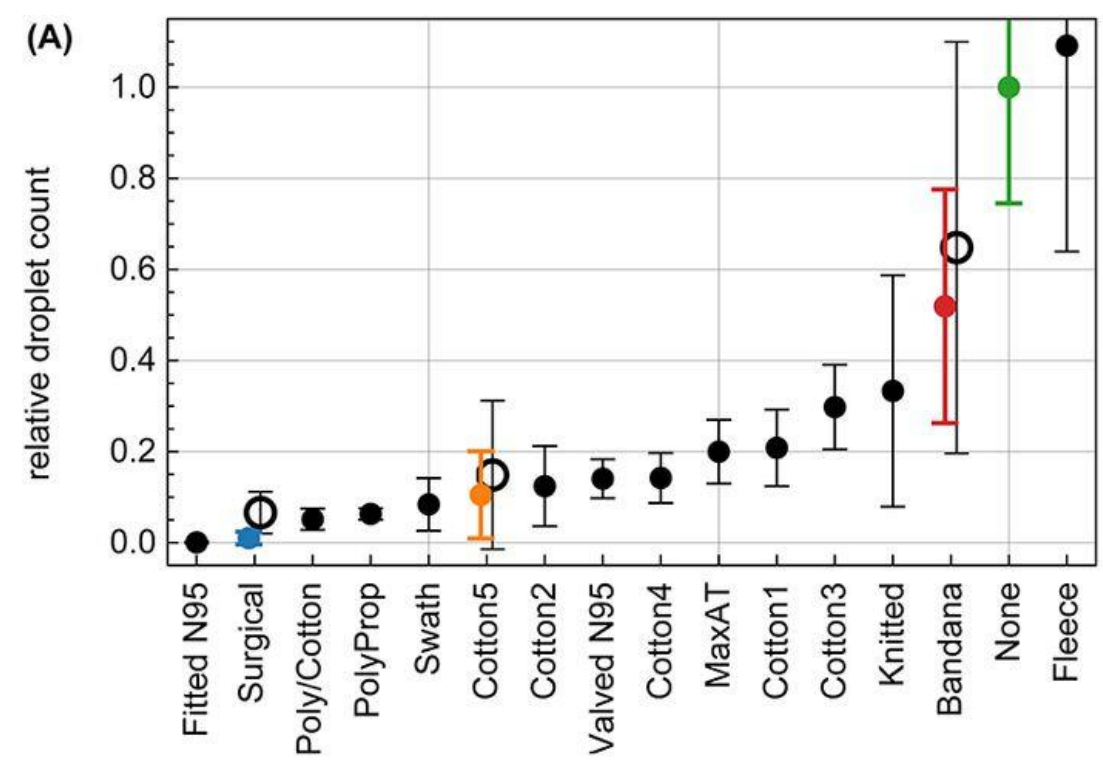

Figure 3. Droplet transmission through face masks. Relative droplet transmission through the corresponding mask.

Liquid is a hard problem for filter and mask, there are also other issues related to liquid. Wilkes etc. [21] conditioned the mask with high humidity air, the conditioned masks shows higher pressure drop and lower efficiency.

There are more new evidence related to liquid droplets effect on mask efficiency such as the most recent work of T. Dbouk and D. Drikakis [22]. They found that after only ten mild cough cycles which produced some liquid droplets or bulk liquid, efficiency can drop $\sim 8 \%$. They expected more significant efficiency reduction for severe coughing events, as well as when wearing a mask for a longer period.

The liquid problem would become graver for face covering for Public than traditional mask donned by professional, which is high efficiency, one time and limited duration use and fixed location use, it is supposed to address this liquid problem, if any, by replacing the mask regularly. Thanks to face covering which is always multiple time used, the occasional virus-shedding wearer of it would become an all-time super spreader as the face covering keep yielding and emitting the aerosols into ambient via the air flow during exhale, the face covering acts as a device cultivating the virus which enter into the ambient via more contagious aerosols rather than large droplets. 
For face covering, there are potential problems such as clog related pressure and efficiency problems, damp related virus proliferation, and evaporation related aerosol generation.

Rather than arguing the wettability of the materials, the MDMN provide a novel comprehensive approaches to attack this liquid problem. The airborne liquid droplet or liquid only contact with solid polymer and small size polymer membrane, both are liquid proof and could be washed and wiped regularly for reuse. Obviously, there is no clog problem, and virus proliferation could be avoided with cleaning.

Aerosol regeneration is a process of heat and mass transfer which is related to five factors, liquid volume, air flow rate, effective contact surface between air and liquid, relative humidity, and filtration efficiency.

Firstly, liquid volume decrease greatly as liquid contact mainly with the solid polymer, much less with membrane, while all liquid contact with face covering and mask; second, there is little or no air flow rate as most of breathing air is via nose, third, without nose flow dilution, the relative humid is high, fourth, not only just utilize hydrophobic surface to minimize the liquid/air contact surface, also the membrane itself has much less surface area than mask and face covering as shown in Figure 4, fifth, the membrane efficiency could be as high as over $99.9 \%$, which means, it could capture part of the aerosol if any.

In a word, MDMN could effectively attack the problem of liquid, including the airborne droplets, and also the bulk liquid such as secretion which was regarded as another route for contamination and block of the filter [23].

Figure 4 show the concept of MDMN, A is just mouth cover without nose cover, and B with nose cover, mouth cover made by solid polymer material such as silicone, with hydrophobic polymer membrane such as PTFE membrane.

Moreover, it can be highly transparent which provides natural, empathetic communication, eliminates barriers caused by traditional masks which often have to be removed for communication.

It is also very resistant to oxidizing agents for all sterilization modes, and is chemically inert, and with excellent mechanical properties, can be reused indefinitely and is easily cleaned with soap and water, or common household disinfectants.

The polymer materials such as silicone is easy processing, the mouth cover can be quickly and affordably produced and distributed. 
While mouth cover control the pathogen source, the nose cover is not necessarily required or just with normal cloth, if for "extra insurance," high efficiency filter could be covered on nose, especially for high risk area such as medical agency. The nose cover could be a dedicated one, or attached to the mouth cover to form one device.

Mask discriminating mouth and nose (MDMN) is more meaningful when reciprocity personal/public protection (RPPP) is adopted, its advantages would become clearer comparing with the normal mask and face covering.
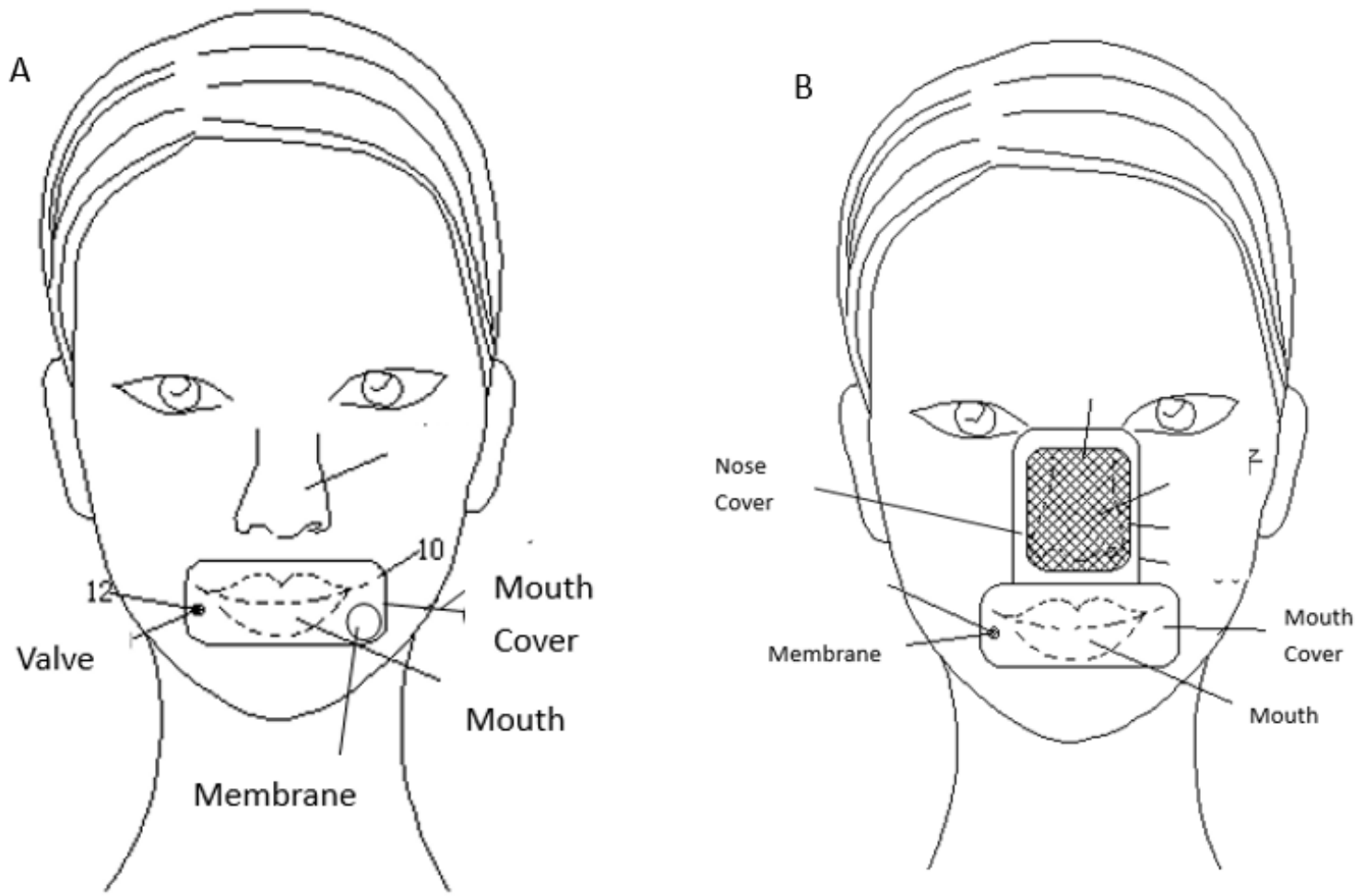

Figure 4. The concept of MDMN, A is just mouth cover without nose cover, and $\mathrm{B}$ with nose cover.

\section{Comparison and Advantages}

The comparison falls into four aspects: efficiency and efficacy, tolerance and comfort, cost and waste, and civil rights and public interest.

\subsection{Efficiency and Efficacy}

The discussion is simply based on a group with 2 person $\mathrm{A}$ and $\mathrm{B}$, rather than multiple person for brevity. One of them is in infection but it is not identified, so reciprocity protection is required, either wear MDMN or wear masks, before comparison, some parameters need to be defined. 


\subsubsection{Parameters}

Protection Factor (PF) was been used for assessment of the personal protection equipment [24].

The Inward Protection Factor (IPF) is calculated by dividing the particle concentrations outside the MDMN or mask $\left(c_{\text {out }}\right)$ by those inside the MDMN or mask $\left(c_{\text {in }}\right)$ :

$\mathrm{IPF}=c_{\mathrm{out}} / c_{\text {in }}$

The IPF is related to filtration efficiency $(\zeta)$ and face-seal leakage factor $(\Phi)$,

$\mathrm{PF}=1 /(1-\zeta \Phi)$

For reciprocity personal/public protection (RPP), two more parameters need to be defined, the first is onward protection factor OPF, and it is related to protect others not the wearer, it calculated by dividing the particle numbers generated by wearer $\left(N_{\mathrm{G}}\right)$ by those emitted into the air $\left(N_{\mathrm{E}}\right)$ :

$\mathrm{OPF}=N_{\mathrm{G}} / N_{\mathrm{E}}$

The PF is related to filtration efficiency $(\zeta)$ and face-seal leakage factor $(\Phi)$,

$\mathrm{OPF}=1 /(1-\zeta \Phi)$

Another is reciprocity protection factor RPF, it is related reciprocity protection, an integration of both IPF and OPF, as stated above, the particles transmission is not only related to the particles numbers, also related to the particles itself quality, the momentum and virus content. For momentum, it is related to the particles effect, represented by a dispersion factor $\mathrm{D}$, for virus content, the professional expressed below, namely, the titer of aerosolized viable virus is expressed in 50\% tissue-culture infectious dose (TCID50) per liter of air [25]. Here, the factors of the effect of virus Represented by $\mathrm{V}$

$\mathrm{RPF}=(\mathrm{OPF} \times \mathrm{IPF})(\mathrm{DV})$

\subsubsection{Comparison}

we assumed 13 scenarios as showing in table 1, N95, SM, MDMN1, FC1,FC2, MDMN2, FCL, N95L, SML, MDMN3,MDMN4, MDMN5,FCLA, it is assumed that mouth generated $95 \%$ of particles, nose $5 \%$ (in fact, real number is less than 5\%). For tight fitting, for membrane with efficiency 99\%, N95 with efficiency $95 \%$, surgical mask SM with efficiency $80 \%$, face covering FC with efficiency, less than $60 \%$ for onward filtration, less than $30 \%$ inward filtration; for loose fitting,N95L with efficiency 38\%, surgical mask SM with efficiency 
$34 \%$, face covering with efficiency FC, $24 \%$ for onward filtration, $12 \%$ inward filtration

There are many researches [26-34] related to the efficiency face covering, but the data is much widely distributed, varying from $3 \%$ [27] to $90 \%$ [32] in filtration efficiency. Given there is no quality control and specification for the face covering, the most optimistic estimation of efficiency for face mask for onward filtration should be less than $60 \%$, Face coverings are not classified as PPE (personal protective equipment), but are instead largely intended to protect others, not the wearer, in fact, there is a less large droplets for inward air filtration considering the fact that the onward filtration remove large droplets and the large droplets can evaporate and turn into aerosolized particles that are 3 to 5- fold smaller [10]. The inward filtration efficiency for aerosol should be much lower than onward filtration, here we randomly assign it less than $30 \%$ efficiency.

The above efficiency is based on tight-fitting scenario, in the case of a loose fitting scenario, gaps (as caused by an improper fit of the mask) can result in over a $60 \%$ decrease in the filtration efficiency [26].

Facemasks and face coverings reduce particles exposure by a combination of the filtering action of the filter and the seal between the mask and the face. The filtration efficiency of masks for specific particles depends on a variety of factors which is dynamic rather than constant during the process: the structure and composition of the filter, gas velocity, shape and tightness of fit, Although any material may provide a physical barrier to an infection, if it does not fit well around the nose and mouth, or the material freely allows infectious particles to pass through it, then it will be of no benefit for any good mask or face covering. The breathing comfort level of the masks will lead to the variation of the above factor, when the mask is not capable of accommodating the breathing demand of the wearer, then the device will impose an extra breathing load on the wearer [35], which means the gas velocity will increase, more leakage occur even under tight-fitting situation, more liquid droplets produce, all of these lead to lower efficiency.

For mask and face covering, even tight-fitting, the efficiency varies during the process, or exactly say, decay with the period of time.

For MDMN, it is of much better fitting for polymer materials and dedicated mouth cover and nose cover without compromise of the shape of mouth and nose, second, the breathing comfort level dramatically improved and the 
breathing does not affect the mouth cover if any effect. So the MDMN keeps a stable high efficiency for the whole process.

Table 1 show tight fitting (N95, SM, and FC1, FC2), loose fitting (N95L, SML, and FCL) and variant MDMN, also show the liquid droplet effect related face covering FCLA.

Below just present detailed calculation process for some cases, others omitted.

\subsubsection{N95, MDMN1, MDMN3}

For N95 situation: both A and B wear N95 mask with efficiency 95\%.

For MDMN1, both wear MDMN with mouth has membrane with efficiency $99 \%$ and nose cover equivalent to N95 with efficiency 95\%, it is assumed that mouth generated $95 \%$ of particles, nose $5 \%$, the average efficiency for onwards is $98.8 \%$, for inward $95 \%$ as for inhale mainly via nose.

For MDMN3, both wear MDMN with mouth has membrane with efficiency $99 \%$ and nose cover equivalent to surgical mask with efficiency $80 \%$, No face leakage is assumed.

For N95, both OPF and PF are 20 based on 95\% efficiency, reciprocity protection factor $\mathrm{RPF}_{\mathrm{N} 95}$ is:

$\mathrm{RPF}_{\mathrm{N} 95}=(20 \times 20)(\mathrm{D} \mathrm{V})_{\mathrm{N} 95}=400(\mathrm{D} \mathrm{V})_{\mathrm{N} 95}$

For MDMN1, OPF is 83.3 , and PF 20, reciprocity protection factor $\mathrm{RPF}_{\mathrm{MDMN}}$ is:

$\mathrm{RPF}_{\mathrm{MDMN}}=(83.3 \times 20)(\mathrm{D} \mathrm{V})_{\mathrm{MDMN}}=1666(\mathrm{D} \mathrm{V})_{\mathrm{MDMN}}$

$\mathrm{RPF}_{\mathrm{MDMN}} / \mathrm{RPF}_{\mathrm{N} 95}=(1666 / 400)(\mathrm{D} \mathrm{V})_{\mathrm{MDMN}} /(\mathrm{D} \mathrm{V})_{\mathrm{N} 95}=4.2(\mathrm{DV})_{\mathrm{MDMN}} /(\mathrm{D} \mathrm{V})_{\mathrm{N} 95}$

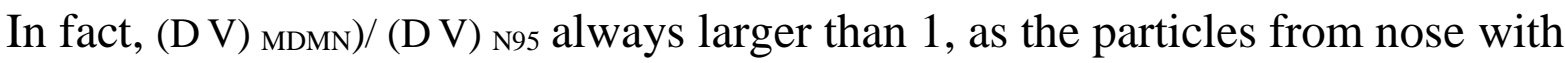
lower momentum and less virus content.

For MDMN3, reciprocity protection factor $\mathrm{RPF}_{\mathrm{MDMN} 3}$ is 250 / (DV) MDMN3

It means that Mouth covering with nose cover equivalent to surgical mask offer the same level protection with the N95, Mouth covering with nose equivalent to N95 better protection against N95.

\subsubsection{MDMN2, SM, FC1}

The reciprocity protection factor for MDMN2 (namely only mouth cover without nose cover), $\mathrm{RPF}_{\mathrm{MDMN} 2}$ is: 16.7 (DV) MDMN2.

The reciprocity protection factor for SM (namely surgical mask), RPF ${ }_{S M}$ is: 25(DV) SM. 
The reciprocity protection factor for $\mathrm{FC1}$ (namely face covering), $\mathrm{RPF}_{\mathrm{FC} 1}$ is: 3.5(DV) $\mathrm{FCl}$.

It means that only Mouth cover offer the same level protection with the surgical mask, even better protection if consider the DV effect, and much better protect against the face covering.

Table 1: comparison between MDMN and mask/face covering

\begin{tabular}{|c|c|c|c|c|c|c|}
\hline \multirow{3}{*}{ Type } & \multirow{3}{*}{ Description } & \multicolumn{2}{|c|}{ Filtration efficiency (\%) } & \multirow{3}{*}{ OPF } & \multirow{3}{*}{$\mathrm{PF}$} & \multirow{3}{*}{ RPF } \\
\hline & & outward & inward & & & \\
\hline & & Mouth/nose & Mouth/nose & & & \\
\hline $\begin{array}{l}\text { MDMN } \\
1\end{array}$ & $\begin{array}{l}\text { Polymer Mouth cover, } \\
\text { N95 equivalent nose cover, } \\
\text { Tight fitting }\end{array}$ & $99 / 95$ & $95 / 95$ & 83.3 & $20^{(1)}$ & $1666(\mathrm{DV})$ мDMN1 \\
\hline N95 & $\begin{array}{l}\text { Mouth and nose with N95 } \\
\text { mask, Tight fitting }\end{array}$ & 95 & 95 & 20 & 20 & $400(\mathrm{DV})$ N95 \\
\hline SM & $\begin{array}{l}\text { Mouth \&nose with surgical } \\
\text { mask, Tight fitting }\end{array}$ & 80 & 80 & 5 & 5 & $25(\mathrm{DV})_{\mathrm{SM}}$ \\
\hline$\overline{F C 1}$ & $\begin{array}{l}\text { Mouth \& nose with face } \\
\text { covering, Tight fitting }\end{array}$ & 60 & 30 & 2.5 & 1.4 & $3.5(\mathrm{DV})_{\mathrm{FCl}}$ \\
\hline FC2 & $\begin{array}{l}\text { Mouth \&nose with face } \\
\text { covering, Tight fitting }\end{array}$ & 50 & 15 & 2 & 1.3 & $2.6(\mathrm{DV})_{\mathrm{FC} 2}$ \\
\hline $\begin{array}{l}\text { MDMN } \\
2\end{array}$ & $\begin{array}{l}\text { Polymer Mouth cover, tight } \\
\text { fitting, No nose cover }\end{array}$ & $99 / 0$ & $99 / 0$ & 16.7 & $1^{(1)}$ & $16.7(\mathrm{DV})_{\mathrm{MDMN} 2}$ \\
\hline N95L & $\begin{array}{l}\text { Mouth and nose with N95 } \\
\text { mask, Loose fitting }\end{array}$ & 38 & 38 & 1.6 & 1.6 & $2.6(\mathrm{DV}) \mathrm{N95 \textrm {L }}$ \\
\hline SML & $\begin{array}{l}\text { Mouth and nose with surgical } \\
\text { mask, Loose fitting }\end{array}$ & 32 & 32 & 1.5 & 1.5 & $2.3(\mathrm{DV})_{\mathrm{SML}}$ \\
\hline$\overline{F C L}$ & $\begin{array}{l}\text { Mouth and nose with face } \\
\text { covering, Loose fitting }\end{array}$ & 24 & 12 & 1.3 & 1.1 & $1.5(\mathrm{DV})_{\mathrm{FCL}}$ \\
\hline $\begin{array}{l}\text { MDMN } \\
3\end{array}$ & $\begin{array}{l}\text { Polymer Mouth cover, } \\
\text { SM equivalent nose cover, } \\
\text { Tight fitting }\end{array}$ & $99 / 80$ & $99 / 80$ & 50 & $5^{(1)}$ & $250(\mathrm{DV})_{\text {мDMN3 }}$ \\
\hline $\begin{array}{l}\text { MDMN } \\
4\end{array}$ & $\begin{array}{l}\text { Polymer Mouth cover, } \\
\text { FC equivalent nose cover, } \\
\text { Tight fitting }\end{array}$ & $99 / 30^{(2)}$ & $99 / 30$ & 22.7 & $1.4^{(1)}$ & $31.8(\mathrm{DV})_{\text {MDMN } 4}$ \\
\hline $\begin{array}{l}\text { MDMN } \\
5\end{array}$ & $\begin{array}{l}\text { Polymer Mouth covering, } \\
\text { FC equivalent nose covering, } \\
\text { Tight fitting }\end{array}$ & $99 / 20^{(2)}$ & $99 / 20$ & 20 & $1.3^{(1)}$ & $26(\mathrm{DV})_{\text {MDMN5 }}$ \\
\hline FCF & $\begin{array}{l}\text { Mouth and nose with fleece } \\
\text { face covering, Tight fitting }\end{array}$ & -10 & 30 & 0.9 & 1.4 & $1.3(\mathrm{DV})_{\mathrm{FCF}}$ \\
\hline
\end{tabular}

Note: it is assumed that mouth generated $95 \%$ of particles, nose $5 \%$.

(1) The PF for all MDMN is based on nose efficiency

(2) The inward efficiency for nose cover equivalent to FC, take efficiency $20 \%$ or $30 \%$, not $50 \%$ or $60 \%$ as nose only generate small particles as shown in Figure 1B 


\subsubsection{MDMN2, MDMN4, MDMN5}

$\mathrm{RPF}_{\mathrm{MDMN} 2}$ is: $16.7 /(\mathrm{DV})_{\mathrm{MDMN} 2}, \mathrm{RPF}_{\mathrm{MDMN} 4}$ is: $31.8 /(\mathrm{DV})_{\mathrm{MDMN}}, \mathrm{RPF}_{\mathrm{MDMN}}$ is: 26/(DV) MDMN5,

It means that there is not much difference between only Mouth cover, and mouth cover with nose face equivalent to face covering, lower the inward efficiency of nose cover, less the difference between with or without nose cover.

\subsubsection{4, FC1, FC2, N95L, SML, FCL}

The reciprocity protection factor for FC1, FC2, N95L, SML and FCL is: 3.5(DV) $)_{\mathrm{FC} 1}, 2.6(\mathrm{DV})_{\mathrm{FC} 2}, 2.6(\mathrm{DV})_{\mathrm{N} 95 \mathrm{~L}}, 2.3(\mathrm{DV})_{\mathrm{SML}}, 1.5(\mathrm{DV})_{\mathrm{FCL}}$ respectively.

Loose fitting mask (N95 \& surgical mask) have much lower value of the reciprocity protection factor than the tight fitting situations, the N95 loose fitting just has same level value with the face covering tight fitting, but there is not much difference between loose fitting and tight fitting for face covering, and also there is not much difference of the reciprocity protection factor between masks or face covering with difference efficiency for loose fitting situation.

\subsubsection{FCF, FC1, FC2}

The RPF for FCF, FC1, FC2, is 1.3 (DV) $\mathrm{FCF}, 3.5$ (DV) $\mathrm{FC}_{1}, 2.6 /(\mathrm{DV})_{\mathrm{FC} 2}$, respectively.

FCF, the fleece face covering has a little lower value of RFP due to the droplet effect as described above, but the difference between the fleece face coverings and other face covering is not striking, the worst thing is not the decrease of RPF value, but the FCF act as all-time fomite to generate virus laden aerosols even the wearer without virus shedding.

The comparison is based on a group of two person wearing the same devices, more extensive investigation could be two persons with different devices, and multiple person with different devices.

\subsection{Tolerance and Comfort}

Although the protective mechanisms of masks are largely physical and sometimes chemical, wearing masks come with a host of physiological and psychological burdens[36], the simple masks can interfere with [37, 38]: respiration, thermal equilibrium, communication, feelings of well-being, personal procedures such as eating and sneezing. 
If enough oxygen can be delivered to the tissues during respiration, at least some anaerobic respiration is required, one of the end products of aerobic respiration is carbon dioxide, if it did climb much higher, carbon dioxide can cause disorientation, confusion, and even death [39]

The large skeletal muscles are only about $20 \%$ efficient [40]. Of the energy supplied to the muscles, approximately $80 \%$ ends up as heat. Heat can be lost from the body by convection (usually, air movement), radiation or evaporation via sweating. Nearly half of the body's heat loss in the cold can come from the uncovered head. Covering the face with mask helps to insulate against this large amount of heat loss, Use of masks in hot conditions leads to several difficulties. Discomfort has been related to facial temperatures inside the masks. Facial skin temperatures are more important for comfort than skin temperatures in other parts of the body. Sweat produced inside the masks can accumulate and cause discomfort, interfere with breathing. Accumulated sweat can cause a mask to slip on the face and promote leakage [41].

Wearing masks can sometimes make communication more difficult [42-44] especially for people who have trouble speaking or hearing. Masks muffle sound, making it more difficult to understand speech and some higherpitched voices [45]. Masks take away our ability to read lips and see facial expressions, which help us better understand what we're hearing. Speaking with a mask can be hard for people with communication problems, like aphasia or voice problems. Masks can be uncomfortable for people who wear hearing aids or cochlear implants.

Personal procedures, eating, drinking, scratching one's face, blowing one's nose, are not possible while wearing masks. The inaccessibility of the face may generate considerable tension in the mind of the wearer, especially if the reason to access the face is due to some particularly sensitive need [41]

There are two basic principles relevant to mask use [41]: First, Work cannot usually be performed as long or as hard while wearing a respirator compared to when respirators are not worn. Second, there is a great deal of wearer variability. Some wearers can tolerate mask with high inspiratory or expiratory resistance, while others cannot. Some wearers are much more anxious about wearing masks than others. Some wearers can tolerate hot, humid conditions inside masks, whereas others cannot. Because of this variability, each wearer must be treated as an individual.

The two principles above get more highlighted during COVID-19 pandemic as mask wearing has transformed from professional and occupational use by professional workers to everyday use for everyone. 
Training in the use of masks is essential [46], professionals are trained to put them on correctly and eliminate anxiety [47], but the public is not. When responding to COVID-19 outbreak, Masks was not well tolerated by public, especially for westerners who are not accustomed to wearing them for extended periods. There are much more difficulties with mask for public than professionals. Problems with mask tolerability have been attributed to overall discomfort[48-55]; including difficulty breathing [51-55], facial irritation[5355],warmth [51], diminished visual [51], dry eye [56], lens fogging [57] ; vocal [43], or auditory acuity [44] ; excessive humidity [48] or heat [48]; headaches [54,55,58], facial pressure [48]; skin irritation or itchiness [48,59]; excessive fatigue or exertion [48,50]; malodorousness [48]; anxiety or claustrophobia [5961]; mask contamination [55]; and also factors of culture and ideology or personal reason, including fear [62,63], stigma [51], shameful, not cool, a sign of weakness [64], Loneliness [65], lack of empathy [66], replacing smile with Smize (Smile With Your Eyes) [67], unmanly emasculation [68], loser [69] etc.

For MDMN, comfortability is of paramount importance, Behaviours are important when advising a population. People are reluctant to don any kind of uncomfortable device regularly, let alone tolerate it for a long time, or just pretend to wear it, which is useless or even worse as People can get a false sense of security from it.

MDMN includes the "near zero penetration" mouth cover for strictly source control, with options of nose cover including the option of no cover at all depend on applications, it is meant to guarantee sustainable comfortability, most importantly of breathing and thermal for most common applications when minimum face area is covered by only mouth cover without any intervene of nose breathing. It is expected that wearer overlook the device and behave without attention and the problems related will automatically disappear.

\subsection{Cost and Waste}

To prevent virus transmission, the use of PPE, such as medical masks and gloves, by medical staff and health workers, and later on by ordinary citizens became essential. The demand for PPE increased significantly worldwide.

The mandatory use of PPE by the public increased significantly. Increased PPE demand led to increased production. As an example, by the end of February, the daily production capacity of masks in China more than quintupled to 110 million units, the National Development and Reform Commission said [70]. 
According to a study in Environmental Science \& Technology [71], the world is using an estimated 129 billion disposable masks each month during the pandemic. The energy consumption of masks production to fulfil the forecasted demand is $4.6 \mathrm{PJ} /$ month [72].

The GHG footprints of N95, surgical masks and cloth covering are suggested as $\sim 5 \times 10-2-6 \times 10-2 \mathrm{~kg} \mathrm{CO} 2 \mathrm{eq} / \mathrm{single}$ use. The cloth mask is having a GHG footprint of $\sim 6 \times 10-2 \mathrm{~kg} \mathrm{CO} 2 \mathrm{eq} / \mathrm{pcs}[73,74]$.

PPE are partially or completely based on polymers such as PE, PA, PP and PET. The N95 masks are made of plastics such as polypropylene (PP) and polyethylene terephthalate (PET). Similarly, surgical masks are made of nonwoven materials that often incorporate other polymers such as polyethylene (PE), PP and PET [75], [76], Such polymers are derived from fossil fuel resources and present low degradability in open environments. Such masks will likely degrade into smaller microplastic pieces [73]. They are among the most commonly found polymers found in terrestrial and marine debris and, in the micro-size ( $1 \mu \mathrm{m}-5 \mathrm{~mm}$, [77]), are known to induce deleterious effects on several aquatic species [78]. Thus, the disposal of such items in open fields will endure the "never-ending-story" of plastics in the environment.

In most cases, PPE will likely end up discarded without precautionary measures in regular municipal solid waste, or worse, littered in the environment. Incorrect disposal of disposable masks have been found littering in several public places. For instance, a considerable amount of disposable masks was observed in a 100 m stretch in Soko's islands beach, Hong Kong, during an environmental survey carried out by the NGO Oceans Asia [79].

According to a WWF report, "if just $1 \%$ of the masks were disposed of incorrectly and dispersed in nature, this would result in as many as 10 million marks per month polluting the environment" [80].

However, the COVID-19 pandemic has clearly outgrown the perceived threat of plastic pollution, leading to a sudden shift in the hierarchisation of values, i.e., where health is considered as a value in spite of environmental care, which shows a clear decrease in its perceived importance [81].

The mandatory use of masks will contribute with a great share. For instance, in United Kingdom (66.7 million inhabitants), it is predicted that if every citizen used one masks per day would generate at least 60000 tonnes of contaminated plastic waste [82]. 
Experts say that face masks are made of multiple layers of different polymers, making them much harder to recycle [83].

With medical and municipal solid waste generated being considered as potentially infectious during COVID-19 pandemic, incineration and landfilling are being prioritised over recycling, which will result in a deterioration on air quality in a medium- to long-term [73]. Production of GHG, such as $\mathrm{CO}_{2}$ and $\mathrm{CH}_{4}$, is released in significant amounts during plastic waste decomposition in landfills, or during the burning of plastics waste [73]. Open burning of plastics waste can also release other hazardous chemicals such as heavy metals, dioxins, PCBs, dioxins and furans, which are linked to health risks allied to respiratory disorders.

The MDMN greatly eliminate the waste and cost from masks and face covering by reuse, the mouth cover could be used unlimited times, nose cover only used for very limited area and could be also reused as there is not efficiency drop issue related liquid drops. The environment impact and economic cost resulting from MDMN will be minimized and much less than that from the present masks and face covering.

\subsection{Civil Rights \& Public Interest}

According to \#Masks4All, an all-volunteer org, among the most of 198 countries listed, masks are required or recommended [84], for all U.S. States except South Dakota, masks are required state-wide or part of state [85]. Thanks to public effort, Masks are mandatory in plenty of countries around the world. However, skirmishes between mask detractors and store staff have been well documented over social media [86, 87]. The most recent report from Mirror [88] say: A craft X Factor star bragged how he made a can of Pringles' last four hours so he could dodge wearing a face mask on his flight to Tenerife. The conflict between public interest and individual resistance remained, and also between the decision maker of public policy.

Georgia Governor Sued Atlanta Mayor to Block Mask Rules and said, "While we all agree with that wearing a mask is effective, I am confident that Georgians don't need a mandate to do the right things, I know that Georgians can rise to this challenge and they will" [89].

As New York Times opinion wrote [90] "You cannot force public trust; you have to earn it". Science could help although "An epidemic is not only technical and medical - they are not cured only by science or vaccines." [90] 
Unlike Wearing masks against air pollution on smoggy days only for personal protection, wearing masks during pandemic is binary, the masks for pandemic have two sides, "Don't get it" for personal and "don't spread it" for public, the binary feature is the root of the controversy.

MDMN approach try to root out the binary feature and get it rootless. There is a clear discrimination of functions, the mouth cover is for source control to protect public, and the nose cover for personal protection is optional of one's free will. Considering that the mouth cover offer the greatest comfort of breathing and thermal comfort, and communication convenience with transparent cover, Balancing the safety of the general public while accommodating people with legitimate individual liberties and their need for comfort is attainable. It would help to end the quandary with compulsory mouth cover and optional nose cover.

When mouth cover is identified as the public protection device, it is plausible for public to offer it free for individual, which is meaningful when masks are yet another thing to remember when walking out the front door. What matters most is that people are required and also choose to wear a mouth cover when they are indoors or in close proximity to others - and that choice needs to be rendered as effortless as possible. And, most of all, the "easily left behand" masks are a constant reminder of what we so desperately want to forget: that despite all of our sacrifices, the pandemic hasn't gone anywhere.

The reusable polymer mouth covers could act as safe public utensil like the forks and knife offered in restaurants, when their sterilization standard is same with the cutlery, no concern should be aroused as they are less sensitive than cutlery.

\section{Summary \& Conclusion}

Jillian J. Jordan et al. [91] investigated which framing, including treatment emphasizing personal, public, or personal and public benefits of prevention, is more effective for fostering intentions to engage in prevention behaviours. They found that the public treatment was more effective than the personal treatment, and no less effective than the personal+public treatment, although sometimes all three treatments were similarly effective. Thus the reciprocal personal/public protection should be prioritized somehow, while masks are haunting and unforgettable imagines tagged as personal protection equipment, MDMN is born just to serve the purpose. 
Source control is imperative for intervention of COVID-19 due to the transmission from people with asymptomatic or mild symptoms. transmission from people presymptomatic or asymptomatic is a major contributor to the rapid spread of SARS-CoV-2 around the world [92,93], 80\% of infections could be attributed to spread from undocumented cases. Presumably the undocumented patients were asymptomatic or had only extremely mild symptoms [94]. New studies show viral loads of the coronavirus are especially high among children and youths, who can unknowingly spread it for weeks [95]. The infected children were shown to have a significantly higher level of virus in their airways than hospitalized adults in ICUs for COVID-19 treatment, meaning they are more contagious, regardless of their susceptibility to developing COVID-19 infection [96].

The new knowledge that mouth is a primary, active and dominant source of the virus has been well established with the published data and the information from epidemiological studies documenting the airborne spread of viral infections from as early as 1940s to most recent. The existing gaps in our knowledge of this field is then identified. MDMN is just based on these new knowledge and focused on the mouth source control.

It is worthwhile to classify the source when source control measures are taken, there are primary, secondary and also third degree source, mouth is the primary source, air, water, surface and mask etc. can act as secondary sources, and hand could be act as a third degree source; the source can be active or passive or between them, mouth is an active source, surface is passive source, while nose is less active source. Air and water such as flushing water and flowing water are active source. The source can be host type source which is alive with unlimited virus, and human and animal are of this type, while others are non-host type source such as surface, air and water etc. which is not alive source and with limited virus in quantity and life.

From "source classification" of view, the source control should focus on the active source, the mouth, the primary and dominant host type source is the most important source to pay attention to. Air is the active source, ventilation as effective way to control the air source [97] is the second most important measure required urgently, toilet or urinal flushing water is also active source $[98,99]$ required to control. The surface is passive and also secondary source is less important but was been over treated [100], an obsession with contaminated surfaces distracts from more effective ways to combat COVID-19 and takes limited resources away from more important goals. Public are exhausted \& overloaded by all the information from variety routes such as via the internet and social media which was profoundly vulnerable to misinformation, partisan 
division, ignorance and fraud, to communicate priorities clearly is paramount for public to focus on what matters and what works.

Funnelling our anxieties into surface related treatment such as empty cleaning rituals, would not only be a pitiful waste of time and money, also the waste of energy and natural resources, and moreover, cause more waste detriment to environment as Surface treatment leads to the excessive use and consumption of single-use plastics such as gloves, cleaning products and disinfectants.

Hand is a special source related surface, which is active rather passive, handwashing is a personal hygiene habit to stay healthy, but, it should be placed after mouth cover etc. in the order of magnitude for preventing coronaviruses when hand source is identified as a third level source.

Social distancing itself is not a way for source control, it is meaningful outdoors, and for indoors without proper ventilation, it only means a false sense of security with potential devastating infection, a bus ride turned into a coronavirus super spreader event is a smoking gun [101].

Contaminated face covering is a surface type source, but when it is donned by people, it is just some kind of active source related to people, also some kind of host source linked to the host, it can be a more dangerous source as explained above. The culprit is the liquid droplet emitted from the host.

Liquid droplets, mask fitting, comfort and facial recognition constitute real challenges of mask in addition to efficiency. Polymer mouth cover address these challenge. For example, for facial recognition used for unlocking the phone [102] or for security of bank [103] etc., which was thwarted by face masks [104], the only mouth cover make facial recognition tech accurate, and a preferred transparent polymer would make it even easier, and also the customers' faces could be printed on the reusable polymer mouth cover [105].

Face covering could be replaced with mouth cover, even the most cautious person should feel securer if the fact that the face covering offer almost no protection for wearer is informed.

Mouth cover with nose cover can offer much better protection than professional masks such as N95 masks, for professional people, which is reported to be lack of PPE [106] and with much higher infections [107]. A new study published [108] in Lancet Public Health has found that healthcare workers with adequate personal protective equipment (PPE) have a three-fold increased risk of a 
positive SARS-CoV-2 test, compared to the general population. Those with inadequate PPE had a further increase in risk.

MDMN, or MDMN with ventilation could avoid lockdowns, While people talk about new thinking on Covid-19 lockdowns as an overly blunt and economically costly tool [109] and a failed experiment [110], which is economically costly and create long-term public-health consequences beyond Covid-19, and serious side effects, and difficult to keep in place for long enough to stamp out the virus. MDMN approach alternative strategies could be consider to slow the spread of the epidemic at much less cost. Policy makers need to pursue MDMN with ventilation etc., these more targeted interventions rather than another crippling round of lockdowns.

An effective vaccine has been touted as the magic bullet that will allow the global economy to quickly shift back into gear. All hopes of extinguishing Covid-19 are riding on a still-hypothetical vaccine. And so a refrain has caught on: stay home, close schools, wear masks etc., normal life is on the other side, and we just have to wait - until we have a vaccine. But considering all the uncertainties that remain ahead for a Covid-19 vaccine [111-116], just waiting is a mistake, looking at what it is available and acceptable as very long-term options should be prioritized. MDMN approach is one of the most promising options to ensure that we are best equipped and prepared to fight the pandemic.

Nine months into the Covid-19 pandemic, we are all exhausted, stressed out, and looking for the exit, so hopes for a quick fix are high. But scientists claimed that the pandemic era is coming, we will increasingly provoke new disease emergences and remain at risk for the foreseeable future, and Covid-19 is among the most vivid wake-up calls in over a century. Fauci, along with his colleague Dr. David Morens, wrote in research published [117] in the prestigious journal CELL. "One can conclude from this recent experience that we have entered a pandemic era. The causes of this new and dangerous situation are multifaceted, complex, and deserving of serious examination." They also pointed out "Science will surely bring us many life-saving drugs, vaccines, and diagnostics; however, there is no reason to think that these alone can overcome the threat of ever more frequent and deadly emergences of infectious diseases. It should force us to begin to think in earnest and collectively about living in more thoughtful and creative harmony with nature, even as we plan for nature's inevitable, and always unexpected, surprises." Reciprocal personal/public protection with mask discriminating the mouth and nose could be one of the way for our collectively living.

MDMN, featured with high efficiency protection, high degree comfort, easy wearing, tight-fitting, easy facial recognition \& communication, reusability, 
cost-effective, environment friendly and scale manufacturing more readily and widely etc., is a simple and sustainable solution, the core principle behind MDMN is "less is more", while most of the innovations on mask for Covid-19 add something to it resulting more complexity [16,118-128], MDMN try to get the mask with as less things as possible by focusing on the main function without any sacrifice, but only with significant improvement such as efficiency and comfortability, and simplify it to the great extent, which is essential for ordinary people to keep wearing it properly for protection.

\section{References}

[1] https://www.cdc.gov/coronavirus/2019-ncov/prevent-getting-sick/howcovid-spreads.html

[2] J. S. Kutter, M. I. Spronken, P. L. Fraaij, R. A. Fouchier, S. Herfst, Transmission routes of respiratory viruses among humans. Curr. Opin. Virol. 28, 142-151 (2018).

[3] Renyi Zhanga et al., Identifying airborne transmission as the dominant route for the spread of COVID-19.https://doi.org/10.1073/pnas.2009637117

[4] Syed A. Sattar, Mohammad Khalid Ijaz \& Charles P. Gerba (1987) Spread of viral infections by aerosols, Critical Reviews in Environmental Science and Technology, 17:2, 89-131, DOI: 10.1080/10643388709388331

[5] Schechmeister, I. L., Studies on the experimental epidemiology of respiratory infections, J. Infect. Dis., 87, 128, 1950.

[6] Duguid J.P. The numbers and the sites of origin of the droplets expelled during expiratory activities. Edinb. Med. J. 1945; 52:385-401

[7] S. Asadi et al., Aerosol emission and superemission during human speech increase with voice loudness. Sci. Rep. 9, 2348, https://www.nature.com/articles/s41598-019-38808-z (2019).

[8] L. Morawska et al., Size distribution and sites of origin of droplets expelled from the human respiratory tract during expiratory activities. J. Aerosol Sci. 40, 256-269 (2009).

[9] Fairchild, C. I. \& Stampfer, J. F., Particle concentration in exhaled breath(1987) Am. Ind. Hyg. Assoc. J. 48, 948-949.

[10] Papineni, R. S. \& Rosenthal, F. S. The size distribution of droplets in the exhaled breath of healthy human subjects. (1997) J. Aerosol Med. 10, 105-116. 
[11] C. P. Cummins, O. J. Ajayi, F. V. Mehendale, R. Gabl and I. M. Viola, The dispersion of spherical droplets in source-sink flows and their relevance to the COVID-19 pandemic, Physics of Fluids 32, 083302 (2020); https://doi.org/10.1063/5.0021427

[12] G. Kampf, D. Todt, S. Pfaender, and E. Steinmann, "Persistence of coronaviruses on inanimate surfaces and their inactivation with biocidal agents," J. Hosp. Infect. 104, 246251 (2020). https://doi.org/10.1016/j.jhin.2020.01.022

[13] Yan, J. et al. Infectious virus in exhaled breath of symptomatic seasonal influenza cases from a college community. Proceedings of the National Academy of Sciences of the United States of America 115, 1081-1086, https://doi.org/10.1073/pnas.1716561115 (2018).

[14] Fabian P, Brain J, Houseman EA, Gern J, Milton DK (2011) Origin of exhaled breath particles from healthy and human rhinovirus-infected subjects. J Aerosol Med Pulm Drug Deliv 24:137-147.

[15] https://www.teflexgasket.com/ptfe-membrane.html

[16] Anan Manomaipiboon, Sujaree Pupipatpab, Pongsathorn Chomdee, Pathiporn Boonyapatkul, Thananda Trakarnvanich, The new silicone N99 half-piece respirator, VJRNMU N99: A novel and effective tool to prevent COVID-19. https://doi.org/10.1101/2020.07.23.217372

[17] F. E. Buckland and D. A. J. Tyrrell, "Loss of infectivity on drying various viruses," Nature 195, 1063-1064 (1962). https://doi.org/10.1038/1951063a0

[18] 5. R. Bhardwaj and A. Agrawal, "Likelihood of survival of coronavirus in a respiratory droplet deposited on a solid surface," Phys. Fluids 32, 061704 (2020). https://doi.org/10.1063/5.0012009

[19] Emma P. Fischer, Martin C. Fischer, David Grass, Isaac Henrion, Warren S. Warren, and Eric Westman, Low-cost measurement of facemask efficacy for filtering expelled droplets during speech, science Advances 07 Aug 2020:eabd3083,

DOI:10.1126/sciadv.abd3083, https://advances.sciencemag.org/content/early/2020/08/07/sciadv.abd3083

[20] Rajneesh Bhardwaj, Amit Agrawal. Tailoring surface wettability to reduce chances of infection of COVID-19 by a respiratory droplet and to improve the effectiveness of personal protection equipment. Physics of Fluids, 2020; 32 (8): 081702 DOI: 10.1063/5.0020249

[21] Wilkes AR, Benbough JE, Speight SE, Harmer, The bacterial and viral filtration performance of breathing system filters. M.Anaesthesia. 2000 May;55(5):458-65. doi: 10.1046/j.1365-2044.2000.01327.x.PMID: 10792138

[22] T. Dbouk and D. Drikakis, "On respiratory droplets and face masks," Phys. Fluids 32(6), 063303 (2020). https://doi.org/10.1063/5.0015044,

[23] Wilkes AR, Ferguson RA, Mecklenburgh JS. Ability of breathing system filters to prevent liquid contamination of breathing systems. British Journal of Anaesthesia 1998; 80: 550P. 
[24] Lee SA, Grinshpun SA and Reponen T (2008b). Respiratory Performance Offered by N95 Respirators and Surgical Masks: Human Subject Evaluation with Nacl Aerosol Representing Bacterial and Viral Particle Size Range. Ann Occup Hyg 52:177-185

[25] N. van Doremalen, T. Bushmaker, D. H. Morris, M. G. Holbrook, A. Gamble, B. N. Williamson, A. Tamin, J. L. Harcourt, N. J. Thornburg, S. I. Gerber, J. O. Lloyd-Smith, E. de Wit, and V. J. Munster, "Aerosol and surface stability of SARS-CoV-2 as compared with SARS-CoV-1,” N. Engl. J. Med. 382, 1564-1567 (2020). https://doi.org/10.1056/nejmc200497

[26] Konda A, Prakash A, Moss GA, Schmoldt M, Grant GD, Guha S. Aerosol filtration efficiency of common fabrics used in respiratory cloth masks. ACS Nano 2020; 14: 6339-47. [PMC free article] [PubMed] [Google Scholar]

[27] Amy V Mueller, Matthew J. Eden, Jessica J. Oakes, Chiara Bellini, Loretta A Fernandez, Quantitative Method for Comparative Assessment of Particle Filtration Efficiency of Fabric Masks as Alternatives to Standard Surgical Masks for PPE, doi: https://doi.org/10.1101/2020.04.17.20069567

[28] Mueller AV, Fernandez LA. Assessment of fabric masks as alternatives to standard surgical masks in terms of particle filtration efficiency. medRxiv 2020. 10.1101/2020.04.17.20069567.

[29] Liu C, Diab R, Naveed H, Leung V. Universal public mask wear during COVID-19 pandemic rationale, design, and acceptability. Respirology 2020. 10.1111/resp.13892.

[30] Susanna Esposito, Nicola Principi, Chi Chi Leung, Giovanni Battista Migliori, Universal use of face masks for success against COVID-19: evidence and implications for prevention policies, European Respiratory Journal 2020 55: 2001260; DOI: 10.1183/13993003.01260-2020

[31] Howard J., Huang A., Li Z., Tufekci Z., Zdimal V., van der Westhuizen HM., von Delft A., Price A., Fridman L., Tang L-H., Tang V., Watson G., Bax C., Shaikh R., Questier F., Hernandez D., Chu L., Ramirez C., Rimoin A. Face Masks Against COVID-19: An Evidence Review, 10.20944/preprints202004.0203.v1

[32] S Rengasamy, B Eimer, RE Shaffer, Simple Respiratory Protection Evaluation of the Filtration Performance of Cloth Masks and Common Fabric Materials against 20-1000 nm Size Particles. The Annals Occup. Hyg. 54, 789 798 (2010). 
[33] Catherine M. Clase et al. Cloth Masks May Prevent Transmission of COVID-19: An Evidence-Based, Risk-Based Approach, Annals of Internal Medicine (2020). DOI: 10.7326/M20-2567

[34]. Sousa-Pinto B, Fonte AP, Lopes AA, Oliveira B, Fonseca JA, CostaPereira A, Correaia O. Face masks for community use: an awareness call to the differences in materials. Respirology 2020. 10.1111/resp.13891.

[35]. Clayton, MP, Bancroft, B, Rajan, B. A review of assigned protection factors of various types and classes of respiratory protective equipment with reference to their measured breathing resistances. Ann Occup Hyg. 2002;46:537-547.

[36]. Johnson AT. Human factors and ergonomic aspects of respirator wear. In: Colton CE, Brosseau LM, editors. Respiratory Protection: A Manual and Guideline. Fairfax: Amer. Indus. Hyg. Assoc; 2001. p. 87-92.

[37]. Johnson AT, Grove CM, Weiss RA. Mask performance rating table for specific military tasks. Mil Med. 1993; 158:665-70.

[38]. Johnson AT, Weiss RA, Grove C. Respirator performance rating table for mask design. Am Indus Hyg Assoc J. 1992;53:193-202.

[39]. Johnson AT. Biomechanics and Exercise Physiology: Quantitative Modeling. Boca Raton: Taylor and Francis; 2007

[40]. Johnson AT, Benjamin MB, Silverman N. Oxygen consumption, heat production, and muscular efficiency during uphill and downhill walking. Appl Ergon. 2002;33:485-91.

[41]. Johnson, AT, Respirator masks protect health but impact performance: a review, J. Biol. Engineer. 10, 4 (2016).

[42]. https://www.asha.org/public/Communicating-Effectively-While-WearingMasks-and-Physical-Distancing/

[43]. Martel J, Bui-Xuan EF, Carreau AM, et al. Respiratory hygiene in emergency departments: compliance, beliefs, and perceptions. Am J Infect Control. 2013;41(1):14-18

[44]. Radonovich Jr LJ, Cheng J, Shenal BV, Hodgson M, Bender BS. Respirator tolerance in health care workers. JAMA - Journal of the American Medical Association. 2009;301(1):36-38.

[45]. https://www.hearingreview.com/hearing-loss/health-wellness/how-domedical-masks-degrade-speech-reception 
[46]. LaTourrette T, Patterson DJ, Bartis JT, Jackson BA, Houser A. Protecting Emergency Responders, vol. 2: Community Views of Safety and Health Risks and Personal Protection Needs. Santa Monica: RAND Science and Policy Institute; 2003.

[47]. Offeddu, V., Yung, C. F., Low, M. S. F. \& Tam, C. C. Effectiveness of Masks and Respirators Against Respiratory Infections in Healthcare Workers: A Systematic Review and Meta-Analysis, Clin. Infect. Dis. 65, 1934-1942 (2017).

[48]. Li, Y., Tokura, H.Guo, Y. P. 2005. Effects of wearing N95 and surgical facemasks on heart rate, thermal stress and subjective sensations. Int. Arch. Occup. Environ. Health, 78(6): 501-509.

[49]. Meyer, J. P., Hery, M.Herrault, J. 1997. Field study of subjective assessment of negative pressure half-masks. Influence of the work conditions on comfort and efficiency. Appl. Ergon., 28(5-6): 331-338.

[50]. Shimozaki, S., Harber, P., Barrett, T. and Loisides, P. 1988. Subjective tolerance of respirator loads and its relationship to physiological effects. Am. Ind. Hyg. Assoc. J., 49: 108-116.

[51]. Canini L, Andreoletti L, Ferrari P, et al. Surgical mask to prevent influenza transmission in households: a cluster randomized trial. PLoS One. 2010;5(11):e13998.

[52]. MacIntyre CR, Cauchemez S, Dwyer DE, et al. Face mask use and control of respiratory virus transmission in households. Emerg Infect Dis.

2009;15(2):233-241.

[53]. MacIntyre CR, Seale H, Dung TC, et al. A cluster randomised trial of cloth masks compared with medical masks in healthcare workers. BMJ Open. 2015;5(4):e006577.

[54]. MacIntyre CR, Wang Q, Cauchemez S, et al. A cluster randomized clinical trial comparing fittested and non-fit-tested N95 respirators to medical masks to prevent respiratory virus infection in health care workers. Influenza Other Respir Viruses. 2011;5(3):170-179.

[55]. Chughtai AA, Stelzer-Braid S, Rawlinson W, et al. Contamination by respiratory viruses on outer surface of medical masks used by hospital healthcare workers. BMC Infectious Diseases. 2019;19(1):491.

[56]. https://medicalxpress.com/news/2020-08-maskseyes.html?utm_source=nwletter\&utm_medium=email\&utm_campaign=dailynwletter 
[57]. https://www.visiondirect.co.uk/blog/stop-mask-fogging-glasses

[58]. Lim, E. C., Seet, R. C., Lee, K. H., Wilder-Smith, E. P., Chuah, B. Y. and Ong, B. K. 2006. Headaches and the N95 face-mask amongst healthcare providers. Acta Neurol. Scand., 113(3): 199-202.

[59]. Registered Nurses Association of Ontario, Canada. "SARS Unmasked: Celebrating Resilience, Exposing Vulnerability.”. [Online] Available at http://www.rnao.org/Storage/24/1891_SARS_Report_June_04.pdf

[60]. Bai, Y., Lin, C. C., Lin, C. Y., Chen, J. Y., Chue, C. M. and Chou, P. 2004. Survey of stress reactions among health care workers involved with the SARS outbreak. Psychiatr Serv., 55(9): 1055-1057.

[61]. Morgan, W. P. 1983. Psychological problems associated with the wearing of industrial respirators: A review. Am. Ind. Hyg. Assoc. J., 44(9): 671-676.

[62]. Ferng YH, Wong-McLoughlin J, Barrett A, Currie L, Larson E. Barriers to mask wearing for influenza-like illnesses among urban Hispanic households. Public Health Nurs. 2011;28(1):13- 23.

[63]. Larson EL, Ferng YH, Wong-McLoughlin J, Wang S, Haber M, Morse SS. Impact of nonpharmaceutical interventions on URIs and influenza in crowded, urban households. Public Health Rep. 2010;125(2):178-191.

[64]. Capraro, V., \& Barcelo, H. (2020, May 11). The effect of messaging and gender on intentions to wear a face covering to slow down COVID-19 transmission. https://doi.org/10.31234/osf.io/tg7vz

[65]. Nickell LA, Crighton EJ, Tracy CS, et al. Psychosocial effects of SARS on hospital staff: survey of a large tertiary care institution. Cmaj. 2004;170(5):793798

[66]. Wong CK, Yip BH, Mercer S, et al. Effect of facemasks on empathy and relational continuity: a randomised controlled trial in primary care. BMC Fam Pract. 2013;14:200.

[67]. https://www.wsj.com/articles/smize-mask-coronavirus-pandemic-covidtyra-banks-reopen-restaurants-11598463705?mod=djemHL_t

[68]. https://blogs.scientificamerican.com/observations/masks-andemasculation-why-some-men-refuse-to-take-safety-precautions/ 
[69]. https://hbr.org/2018/11/how-masculinity-contests-undermineorganizations-and-what-to-do-about-it

[70]. http://www.xinhuanet.com/english/2020-03/02/c_138835152.htm

[71]. J.C. Prata, A. Silva, T.R. Walker, A.C. Duarte, T.A.P. RochaSantos,COVID-19 Pandemic Repercussions on the Use and Management of Plastics, Environ. Sci. Technol., 54 (2020), pp. 1-6, 10.1021/acs.est.0c02178

[72]. Jiří Jaromír Klemeš, Yee Van Fan, Peng Jiang. The Energy and Environmental Footprints of COVID-19 Fighting Measures - PPE, Disinfection, Supply Chains. Energy 2020, 118701. https://doi.org/10.1016/j.energy.2020.118701

[73]. Ecochain, 2020. The rise of the face mask: What's the environmental impact of 17 million N95 masks? <ecochain.com/knowledge/footprint-facemasks-comparison/> accessed 26 July 2020.

[74]. Allison, A. L., Ambrose-Dempster, E., T Aparsi, D., Bawn, M., Casas Arredondo, M., Chau, C., .Chandler K., Dobrijevic D., Hailes H., Lettieri P., Liu, C., Medda F., Michie S., Miodownik M., Purkiss D, Ward J., 2020. The environmental dangers of employing single-use face masks as part of a COVID19 exit strategy. UCL Press. DOI: 10.14324/111.444/000031.v1.

[75]. J.R. Ajmery, C.J. Ajmeri Nonwoven Materials and Technologies for Medical Application, Woodhead Publishing Limited:, Cambridge, UK (2011)

[76]. P. Martínez Silva, M.A. Nanny Impact of Microplastic Fibers from the Degradation of Nonwoven Synthetic Textiles to the Magdalena River Water Column and River Sediments by the City of Neiva, Huila (Colombia), Water., 12 (2020), pp. 1210-1216, 10.3390/w12041210

[77]. J.P.G.L. Frias, R. Nash Microplastics: Finding a consensus on the definition, Mpb., 138 (2019), pp. 145-147, 10.1016/j.marpolbul.2018.11.022

[78]. L.C. de Sá, M. Oliveira, F. Ribeiro, T.L. Rocha, M.N. Futter Studies of the effects of microplastics on aquatic organisms: What do we know and where should we focus our efforts in the future? Sci. Tot. Environ., 645 (2018), pp. 1029-1039, 10.1016/j.scitotenv.2018.07.207

[79]. NGO Oceans Asia No shortage of masks at the beach. NGO oceans Asia http://oceansasia.org/beach-mask-coronavirus/ (2020), Accessed 16th Jun 2020 
[80]. Italy WWF, in the disposal of masks and gloves, responsibility is required WWF International, https://www.wwf.it/chi_siamo/organizzazione/ (2020), Accessed 8th Jun 2020

[81]. M. Grodzińska-Jurczak, et al. Environmental choices vs. Covid-19 pandemic fear - plastic governance re-assessment, Sr., 4 (2020), pp. 4966, 10.14746/sr.2020.4.2.04

[82]. U.P.W.I. Hub, The environmental dangers of employing single-use face masks as part of a COVID-19 exit strategy.

https://d2zly2hmrfvxc0.cloudfront.net/Covid19-Masks-Plastic-Waste-PolicyBriefing.final.pdf. (accessed 22 July 2020), (2020).

[83]. L.M. Monella Will plastic pollution get worse after the COVID-19 pandemic? Euronews, https://www.euronews.com/2020/05/12/will-plasticpollution-get-worse-after-the-covid-19-pandemic (2020), Accessed 8th Jun 2020

[84]. https://masks4all.co/what-countries-require-masks-in-public/

[85]. https://masks4all.co/what-states-require-masks/

[86]. https://twitter.com/OnlyInLVNV/status/1262335074516692992

[87]. https://www.dailymail.co.uk/news/article-8488515/Woman-screamedbarista-face-mask-feud-wants-half-100K-tip.html

[88]. https://www.mirror.co.uk/3am/celebrity-news/x-factor-star-sharescontroversial-22616065

[89]. https://www.gulf-times.com/story/668437/With-US-divided-on-masksGeorgia-governor-refuses-to-back-down

[90]. https://www.nytimes.com/2020/07/22/opinion/coronavirus-healthexperts.html

[91]. Jordan, J.J., Yoeli, E. and Rand, D.G. (2020), Don't get it or don't spread it? Comparing self-interested versus prosocially framed COVID-19 prevention messaging, Working paper, https://psyarxiv.com/yuq7xCrossRef

[92]. Nathan W. Furukawa, John T. Brooks, and Jeremy Sobel, Evidence Supporting Transmission of Severe Acute Respiratory Syndrome Coronavirus 2 While Presymptomatic or Asymptomatic, https://wwwnc.cdc.gov/eid/article/26/7/20-1595_article 
[93]. Monica Gandhi, M.D., M.P.H., Deborah S. Yokoe, M.D., M.P.H., and Diane V. Havlir, M.D. Asymptomatic Transmission, the Achilles' Heel of Current Strategies to Control Covid-19, May 28, 2020,N Engl J Med 2020; 382:2158-2160,DOI: 10.1056/NEJMe2009758

[94]. Li, R. et al. Substantial undocumented infection facilitates the rapid dissemination of novel coronavirus (SARS-CoV-2). Science 368, 489-493 (2020).

[95]. Roberta L. DeBiasi, MD, MS; Meghan Delaney, DO, MPH, Symptomatic and Asymptomatic Viral Shedding in Pediatric Patients Infected With Severe Acute Respiratory Syndrome Coronavirus 2 (SARS-CoV-2) Under the Surface, August 28, 2020. doi:10.1001/jamapediatrics.2020.3996

[96]. Lael M. Yonker, MD et al. , Pediatric SARS-CoV-2: Clinical Presentation, Infectivity, and Immune Responses, August 19, 2020DOI:https://doi.org/10.1016/j.jpeds.2020.08.037

[97]. Somsen GA, van Rijn C, Kooij S, et al. . Small droplet aerosols in poorly ventilated spaces and SARS-CoV-2 transmission. Lancet Respir Med 2020; 8: 658-659. doi:10.1016/S2213-2600(20)30245-9

[98]. Y.-y. Li, J.-X. Wang, and X. Chen, "Can a toilet promote virus transmission? From a fluid dynamics perspective," Phys. Fluids 32, 065107 (2020). https://doi.org/10.1063/5.0013318,

[99]. Ji-Xiang Wang, Yun-Yun Li, Xiang-Dong Liu, Xiang Cao. Virus transmission from urinals. Physics of Fluids, 2020; 32 (8): 081703

DOI: $10.1063 / 5.0021450$

[100]. Goldman E. Exaggerated risk of transmission of COVID-19 by fomites.

Lancet Infect Dis. 2020; 20: 892-893

[101]. Lin J, Yan K, Zhang J, Cai T, Zheng J. A super-spreader of COVID-19 in Ningbo city in China. Journal of Infection and Public Health. 2020;13:935-37

[102]. https://www.theguardian.com/technology/2020/aug/21/face-masks-givefacial-recognition-software-identity-crisis

[103]. https://www.washingtonpost.com/business/2020/07/22/face-mask-banks/ [104]. https://nvlpubs.nist.gov/nistpubs/ir/2020/NIST.IR.8311.pdf 
[105]. https://www.dezeen.com/2020/02/27/face-recognition-masks-restingrisk-face/

[106]. https://medicalxpress.com/news/2020-08-nursing-homes-short-ppestaff.html?utm_source=nwletter\&utm_medium=email\&utm_campaign=dailynwletter

[107]. https://www.premier.vic.gov.au/protecting-our-healthcare-heroes

[108]. Long H Nguyen, et al. Risk of COVID-19 among front-line health-care workers and the general community: a prospective cohort study, DOI:https://doi.org/10.1016/S2468-2667(20)30164-X

[109]. https://www.wsj.com/articles/covid-lockdowns-economy-pandemicrecession-business-shutdown-sweden-coronavirus11598281419 ? $\bmod =$ searchresults\&page $=1 \&$ pos $=4$

[110]. https://www.wsj.com/articles/the-failed-experiment-of-covid-lockdowns11599000890

[111]. Chen et al., Mutations strengthened SARS-CoV-2 infectivity. arXiv:2005.14669v1 [q-bio.BM]. arxiv.org/pdf/2005.14669.pdf

[112]. Lizhou Zhang, Cody B Jackson, Huihui Mou, Amrita Ojha, Erumbi S Rangarajan, Tina Izard, Michael Farzan, Hyeryun Choe doi: https://doi.org/10.1101/2020.06.12.148726

[113]. Ewen Callaway, The coronavirus is mutating — does it matter?

Nature $585,174-177$

[114]. https://drive.google.com/file/d/1md_4JvJ8s9fm71YZWlubxbqXanNaQL $\mathrm{Ci} /$ view

[115]. https://edition.cnn.com/2020/09/06/investing/stocks-weekahead/index.html

[116]. https://www.theatlantic.com/health/archive/2020/07/covid-19-vaccinereality-check/614566/

[117]. David M. Morens, Anthony S. Fauci, Emerging Pandemic Diseases: How We Got to COVID-19, Cell, Vol. 182, Issue 5, p1077-1092, Published online: August 15, 2020, DOI:https://doi.org/10.1016/j.cell.2020.08.021

[118]. https://www.pneumask.org/

[119]. https://www.theclearmask.com/product 
[120]. https://www.leaf.healthcare/

[121]. https://en.donutrobotics.com/c-mask

[122]. https://sg.asiatatler.com/society/covid-19-protection-smart-andinnovative-face-masks-from-start-ups

[123]. https://www.eetasia.com/top-10-best-techno-mask-innovations/

[124]. https://www.insider.com/most-creative-face-masks-people-havedesigned-2020-5\#this-face-mask-is-made-from-cardboard-28

[125]. https://interestingengineering.com/25-innovative-examples-of-facemasks-and-face-shields

[126]. Sricharan Chalikonda, Hope Waltenbaugh, Sara Angelilli, Tiffany Dumont, Curt Kvasager, Timothy Sauber, Nino Servello, Anil Singh, Rafael Diaz-Garcia. Implementation of an Elastomeric Mask Program as a Strategy to Eliminate Disposable N95 Mask Use and Resterilization: Results from a Large Academic Medical Center. Journal of the American

[127]. College of Surgeons, 2020; DOI: 10.1016/j.jamcollsurg.2020.05.022 https://www.scientificamerican.com/article/new-design-helps-n95-maskwearers-breathe-easier/

[128]. James D Byrne, Adam J Wentworth, Peter R Chai, Hen-Wei Huang, Sahab Babaee, Canchen Li, Sarah L Becker, Caitlynn Tov, Seokkee Min, Giovanni Traverso. Injection Molded Autoclavable, Scalable, Conformable (iMASC) system for aerosol-based protection: a prospective single-arm feasibility study. BMJ Open, 2020; 10 (7): e039120 DOI: 10.1136/bmjopen2020-039120 